\title{
Which agricultural management interventions are most influential on soil organic carbon (using time series data)?
}

Neal Robert Haddaway ${ }^{1 *}$, Katarina Hedlund ${ }^{2}$, Louise E. Jackson ${ }^{3}$, Thomas Kätterer ${ }^{4}$, Emanuele Lugato ${ }^{5}$, Ingrid K. Thomsen ${ }^{6}$, Helene Bracht Jørgensen ${ }^{2}$ and Per-Erik Isberg ${ }^{7}$

\begin{abstract}
Background: Loss of soil organic carbon (SOC) from agricultural land is identified as one of the major threats to soils, as it influences both fertility and the production of ecosystem services from agriculture. Losses of $\mathrm{SOC}$ across regions are often determined by monitoring in different land use systems. Results from agricultural field experiments can reveal increasing SOC stocks after implementation of specific management practices compared to a control, though in time series experiments the relative rate of change is often negative and implying an overall loss. Longterm agricultural field experiments are indispensable for quantifying absolute changes in SOC stocks under different management regimes. Since SOC responses are seldom linear over time, time series data from these experiments are particularly valuable.

Methods: This systematic review is based on studies reporting time series data collated in a recently completed systematic map on the topic restricted to the warm temperate climate zone and the snow climate zone. These 53 studies were identified and selected systematically according to CEE guidelines. An update of the original search for studies will be repeated using Web of Science and Google Scholar to include newly published academic and grey literature in the time since the original search was performed in September 2013. Studies will be subject to critical appraisal of the internal and external validity, followed by full data extraction (meta-data describing study settings and quantitative study results). Where possible, studies will be included in a quantitative synthesis using time series meta-analytical approaches. The implications of the meta-analytical findings will be discussed in terms of policy, practice and research along with a discussion of the nature of the evidence base.
\end{abstract}

Keywords: Agriculture, Tillage, Fertilization, Crop rotation, Amendment, Farming, Conservation, Carbon sequestration, Long-term field experiments, Time series data

\section{Background}

Loss of soil organic carbon (SOC) from agricultural land is identified as one of the major threats to soils, as it influences both soil fertility and the provision of ecosystem services. It has been estimated that to date US soils may have lost between 30 and $50 \%$ of the SOC that they

\footnotetext{
*Correspondence: neal.haddaway@eviem.se;

neal_haddaway@hotmail.com

${ }^{1}$ Mistra Council for Evidence-Based Environmental Management (EviEM), Royal Swedish Academy of Sciences, P.O. Box 50005, 10405 Stockholm, Sweden

Full list of author information is available at the end of the article
}

contained prior to the establishment of agriculture [1]. SOC monitoring in Europe also shows depleting stocks especially in areas where cereal production is prominent [2]. Thus, management of agricultural soils has a potential to mitigate climate change through SOC sequestration [3-5]. Promoting SOC stocks in agricultural soils not only potentially mitigates climate change but can greatly increase soil fertility $[6,7]$ and improve physical and biological properties of the soil [8], through: a decrease in bulk density; increased water-holding capacity; improved soil structure and enhanced microbial activity [9]. The appreciation of SOC for both mitigating climate change 
and making agriculture more sustainable is increasing globally. This subject is particularly relevant in Europe, because of the recent EU decision [10] to introduce mandatory accounting of cropland and grazing land management for EU Member States. Furthermore, the FAO has expressed its interest in SOC preservation by hosting the global soil partnership and the intergovernmental technical panel on soils, with the aims of contributing to environmental wellbeing in the following ways: by preventing soil erosion and degradation; by reducing greenhouse gas emissions; by promoting SOC sequestration; by promoting sustainable use of agricultural inputs for soil health and ecosystems management [11].

The rate of change of SOC is often determined across regions using monitoring data from SOC in different land use systems, and the evaluation of SOC sequestration is often confounded by an array of management practices and differences in soil types that need to be accounted for with modelling or statistical approaches [12]. On the other hand, results from local agricultural experiments can provide valuable resolution for detecting changing SOC stocks after implementation of specific management practices in comparison to a control. Such experiments do not account for the rate of change of the SOC stocks and typically only evaluate differences at one point in time. However, in some long-term agricultural experiments SOC stocks are recorded through time and there is thus a possibility to estimate the rate of change due to management practices [13]. In order to avoid evaluations of relative differences of management effects on SOC, here we set out an approach for analysis within systematic review methodology using data from time series studies that may provide valuable evidence of rates of change of SOC under various agricultural management regimes. Long-term time series data have been published from a range of agricultural experiments (e.g., [14]) and it is therefore possible to compile overall rates of change of SOC stock from a diverse spectrum of agricultural experiments. Such information can allow us to evaluate whether SOC is being lost or sequestered under different management regimes.

Sanderman and Baldock [13] have highlighted the importance of determining the rate of SOC change and show that even though a single management practice can be shown to promote stocks, the rate of change may be negative overall; for example, see experiments in Australia where management depleted the SOC stock (see Fig. 1). Furthermore, there is evidence from long-term experiments in Europe and the US showing that SOC decay rate can be negative even though straw is returned, low tillage practiced and high amounts of fertiliser used $[15,16]$.

This systematic review continues on from a recently completed systematic map of the impacts of agricultural

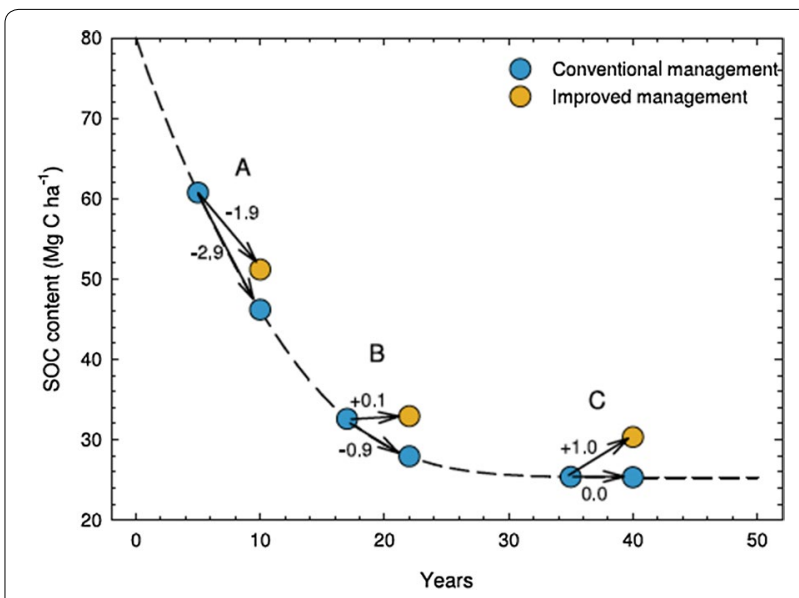

Fig. 1 Soil organic carbon (SOC) content over time for conventional and improved management. The graph shows how a hypothetical management intended to improve SOC may have a relatively higher SOC content at a specific point in time than conventional management, but the absolute level of the stock of SOC is declining at an exponential rate. Reproduced under CCBY license from [13]

management on SOC (Haddaway et al. [18]). This map identified a substantial volume of relevant research from across the warm temperate and the snow climate zones (Köppen-Geiger Climate Classification [17]). The review highlighted that the vast majority of evidence was performed as 'snapshot' research, with no or limited baselines. A small subset of research was undertaken over long time scales (i.e., $>30$ years) and with multiple measurements over time. It is this research that allows for rates of SOC stock change to be calculated across a range of different management practices and environmental conditions.

\section{Identification of the topic}

Stakeholders contacted by the boundary organisation Mistra EviEM (http://www.eviem.se) noted a great interest in a range of agricultural management practices: in particular the relative efficacy of different methods in reducing SOC decline, or preserving and restoring SOC. Following completion of the systematic map, several subtopics were identified as suitable for full systematic review based on a number of key criteria: the presence of sufficient reliable evidence, the relevance of the topics for stakeholders, the applicability of the topics for the Swedish environment, the benefit of a systematic approach to topics that have received some attention via traditional reviews, and the added value of investigating effect modifiers and sources of heterogeneity across studies via a large meta-analysis. For one of these topics evidence included long-term data as time series. In addition to meeting the above criteria, time series studies provide 
data suitable for non-linear regression, allowing SOC decay rates to be compared across interventions and time series.

\section{Objective of the review}

The agricultural practices included in this review have been the subject of previous reviews and meta-analyses, but to date no comprehensive review has attempted multiple time series analysis, which we intend to do in a systematic approach to maximise reliability. The objective of this review is to systematically review and synthesise existing research pertinent to a range of agricultural management practices in warm temperate and snow climate zones (see Population below for details) using, as a basis, the evidence identified within a recently completed systematic map [18]. This systematic map aimed to collate evidence relating to the impacts of all agricultural management on soil organic carbon in boreo-temperate regions.

Primary Question Which agricultural management interventions are most influential on SOC (using time series data)?

Secondary Question How do agricultural management interventions interact to affect SOC?

Population Arable soils in agricultural regions from the warm temperate climate zone (fully humid and summer dry, i.e., Köppen-Geiger Climate Classification; $\mathrm{Cfa}, \mathrm{Cfb}, \mathrm{Cfc}, \mathrm{Csa}, \mathrm{Csb}, \mathrm{Csc}$ ) and the snow climate zone (fully humid, i.e., Köppen-Geiger Climate Classification; Dfa, Dfb, Dfc).

Intervention Any agricultural management practice relating to: different types, methods or amounts of amendment or fertilizer additions; tillage intensity and crop rotations.

Comparator Before intervention or different interventions.

Outcome SOC (measured as either concentration or stock).

\section{Methods}

Searches

\section{Original systematic map search}

Searches of 17 academic databases were undertaken as part of the published systematic map between the 16th and 19th September 2013. These academic database searches were supplemented by searches for grey literature via web search engines and organisational websites, and by searches of the bibliographies of 127 relevant reviews and meta-analyses identified during the course of the systematic map. Full details for all searches can be found in supplementary information accompanying the systematic map described in [18].

\section{Search update}

A search update will be undertaken to capture research published since the original search in September 2013. The update will be restricted to one academic database, Web of Science, and one academic search engine, Google Scholar, which has been shown to be effective at identifying both academic and grey literature [19]. Only English language search terms will be used but all articles identified in Danish, English, French, German, Italian, Russian, and Swedish will be included. The choice to reduce the number of citation databases was driven by observations made during the undertaking of the systematic map, where a large number of duplicates was identified in many of the databases used.

In Web of Science the original search string (see below) will be used again to search on 'topic words' with results restricted to just 2013, 2014 and 2015 publication years.

soil" AND (arable OR agricult* OR farm* OR crop* OR cultivat*) AND (till* OR "direct drill"* OR fertili* OR "bio*solid"” OR organic OR manur" OR sewage OR compost" OR amendment" OR biochar* OR digestate* OR "crop residue*" OR "crop straw"* OR mulch* OR "crop rotat" OR break crop* OR grass OR clover ley" OR legume* OR "bioenergy crop" system" "OR "winter crop" OR "spring crop"” OR "summer fallow" OR "catch"crop"” OR intercrop" OR conservation) AND ("soil organic carbon" OR "soil carbon" OR "soil C" OR "soil organic C" OR SOC OR "carbon pool" OR "carbon stock" OR "carbon storage" OR "soil organic matter" OR SOM OR "carbon sequestrat"” OR "C sequestrat"*")

In Google Scholar the following search string will be used and the first 1000 records downloaded for both title and full text searches:

soil AND carbon AND (till* OR "direct drill" $O R$ fertili" $\Theta$ R "bio"solid"*" OR organieOR manur* OR sewage OR compost* OR amendment ${ }^{*}$ OR biochar* OR digestate ${ }^{*}$ OR "crop residue" "OR "crop straw" OR mulch* OR "crop rotat * $\Theta \mathrm{R}$ "break crop" $\mathrm{OR}$ grass $\mathrm{OR}$ "elover ley" $\mathrm{OR}$ legume* OR "bioenergy crop" OR "cover crop" elover"OR "crop" system" "OR "winter erop" erop" $O R$ "summer-fallow" OR "catch"crop" OR intercrop* OR conservation) [striked out text indicates modifications made to the original search string in order to adapt it for Google Scholar].

Up to 1000 search results (ordered by an undisclosed algorithm) for full text searches and title searches restricted to 2013-2015 will be downloaded using a method described in Haddaway et al. [19].

\section{Screening}

A total of 53 studies have already been identified as part of the recent systematic map [18]. These studies were originally assessed according to predefined inclusion 
criteria (see [20]) but have been subject to additional inclusion criteria to ensure relevance for this review: the studies must have been undertaken over a minimum of 30 years; and a minimum of three outcome measurements must have been made over time. Additional studies identified from the search update described above will be assessed for inclusion in the review according to the following predefined inclusion criteria.

Relevant populations: Arable soils in agricultural regions from the warm temperate climate zone (fully humid and summer dry, i.e., Köppen-Geiger Climate Classification; $\mathrm{Cfa}, \mathrm{Cfb}, \mathrm{Cfc}, \mathrm{Csa}, \mathrm{Csb}, \mathrm{Csc}$ ) and the snow climate zone (fully humid, i.e., Köppen-Geiger Climate Classification; Dfa, Dfb, Dfc). Figure 2 displays the geographical regions covered by these zones. These zones were selected due to their relative homogeneity and relevance to the Swedish environment (the nation from which funding this review was provided).

Relevant interventions: Any described agricultural management practice relating to: different types, methods or amounts of amendment (including manure, crop residues, green manure, lime, sewage sludge, processed wood, peat/sediment, domestic waste/compost, bone meal/animal products) or fertilizer additions; tillage intensity (no tillage/direct drill, reduced/conservation tillage, rotational/occasional tillage, conventional tillage, subsoiling); and crop rotations (monocultures, different crop sequences and rotation lengths, legumes, fallow, energy crops, annuals, perennials).

Relevant comparators: Before intervention or different management intervention. Studies may be included if they provide data for single interventions (i.e., no spatial comparators) if time series data are present (see Relevant Study Types below).

Relevant outcomes: Soil C measures, including: soil organic carbon (SOC), total organic carbon (TOC), total carbon (TC), and soil organic matter (SOM). This may be expressed either as a concentration (e.g., g/kg or \%) or as a stock (e.g., $\mathrm{Mg} / \mathrm{ha}$ ).

Relevant study types: Studies must have examined interventions that have lasted at least 30 years to ensure that changes in SOC are detectable [21] and to allow time series to be used in non-linear estimates of net decay or accumulation rates. Studies must involve at least three outcome measurements across this time period. Laboratory, mesocosm (i.e., greenhouse) and modeling studies will not be included unless they also present primary data from field studies.

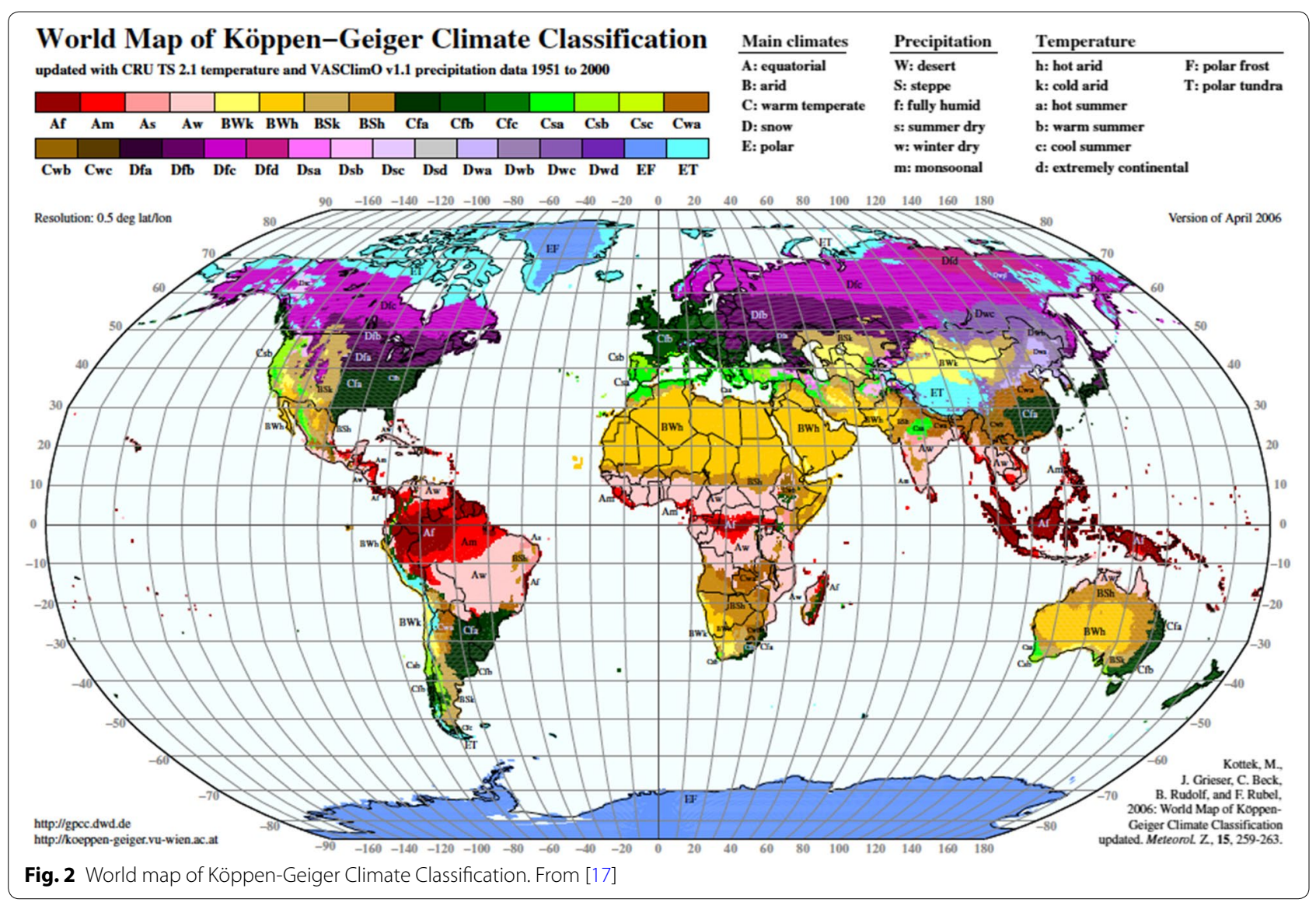


A change in soil management can often lead to a change in bulk density, meaning that SOC stock measurements for specific soil profiles may be inaccurate, since soil profiles themselves may change [22]. Despite the importance of bulk density measurements, however, the body of evidence identified through the original searches of the systematic map included 365 of the total 735 studies that failed to report bulk density, whilst $67 \%$ of the 311 studies on tillage failed to report bulk density. Many of these studies had measured bulk density: indeed, 78 studies only reported SOC stocks alone. In order to make the most of these data we have been inclusive and have not excluded studies that do not report bulk density, since the volume of high-resolution data reported over time-series is low.

Furthermore, in our meta-analysis we will compare rates of change of SOC by estimating the fluctuation over time within each dataset. This measure is therefore a relative one; an annual proportional change. Practically speaking, this will be done by estimating the parameters of the function of each fitted curve (see Synthesis, below). This means that the presence of bulk density measurements will not affect the rate of change of SOC.

Every study identified via the update will be screened through three stages: title, abstract and full text. At each level, records containing or likely to contain relevant information will be retained and taken to the next stage. Where information is lacking (for example where abstracts are missing), the record will be retained in order to be conservative. Following abstract screening full texts will be sought and those that cannot be obtained will be documented as such in the full systematic review. Screening will be performed by one reviewer, with a subset of $10 \%$ of records at abstract level being screened by a second reviewer. A Kappa test [23] will be performed on the dual screening to assess the level of agreement. Where agreement is lower than moderate (kappa $=0.6$ ) discrepancies will be discussed in detail and a further subset screened and tested to ensure improvement in consistency before continuing with screening.

\section{Additional bibliographic checking}

Reviews and meta-analyses identified through screening of results from the search update described above will be assessed separately, examining the bibliographies of each article for potentially relevant articles. As with the screening described above, bibliographic checking will be performed by one reviewer with a subset of $10 \%$ of review bibliographies being checked by a second reviewer to ensure consistency.

\section{Effect modifiers/sources of heterogeneity}

All studies included in this review will be subject to extraction of meta-data (see Data Extraction, below), which will include the extraction of data regarding key sources of heterogeneity. These include: climate zone, latitude, longitude and soil type (classification or texture). These potential modifiers will be used in meta-analyses to account for significant differences between studies, as described below in Synthesis.

\section{Critical appraisal of study validity}

The completed systematic map undertook critical appraisal of the included studies for the purposes or excluding unreliable studies that were highly susceptible to bias or non-generalisable and to assess the reliability of the evidence base. Reasons for exclusion were transparently recorded for all studies (see supplementary information in [18]). In addition to excluding studies that were highly susceptible to bias (such as those lacking details on methods, or those with no replication), five domains were assessed for study reliability for those studies passing this initial assessment of reliability: spatial replication (number of spatial replicates); temporal replication (number of time samples); treatment allocation (e.g., randomized, blocked, purposive); study duration (length of the experimental period); soil sampling depth (the number and extent of soil depth samples taken). For each of these domains, studies were awarded a 0,1 , or 2 for the degree of reliability as described in Table 1 . Where insufficient information was reported a '?' was awarded. See Haddaway et al. [18] for full details of the methods used and results from the systematic map.

This critical appraisal scheme will be used to assess studies identified through the search update. Following this appraisal, every study that has passed stage one of critical appraisal will then be given a 'low' or 'high' reliability rating based on an individual assessment of reliability for each study, and justification will be given in text form. Rating activities will be performed by two reviewers. This rating will be used as a basis for sensitivity analysis in the meta-analyses described below. Critical appraisal will be undertaken by one reviewer and checked for consistency and accuracy by a second reviewer in full.

\section{Data extraction}

Meta-data will be extracted for all studies. This information will include the following information: citation; study location (country, site, climate zone, latitude and longitude); soil type (classification or percent clay/silt/ sand); intervention type [broad group (i.e., amendments, crop rotation, fertilizer, tillage), number of treatments, detailed treatment description]; study description (start year, duration, treatments investigated, cropping system, experimental design); sampling strategy (spatial and temporal replication, subsampling, soil sampling depth, SOC measurement method). In addition, quantitative 
Table 1 Critical appraisal criteria for agricultural experiments with time series data on soil organic carbon (SOC)

\begin{tabular}{|c|c|c|}
\hline Variable & Value & Score \\
\hline \multirow[t]{3}{*}{ Spatial (true) replication } & 2 replicates & 0 \\
\hline & $3-4$ replicates & 1 \\
\hline & $>4$ replicates & 2 \\
\hline \multirow[t]{3}{*}{ Temporal replication } & $\leq 3$ replicates & 0 \\
\hline & 4-6 replicates & 1 \\
\hline & $>6$ replicates & 2 \\
\hline \multirow[t]{2}{*}{ Treatment allocation (as described for the full experimental design) } & Purposive (selective) & 0 \\
\hline & split-/strip-plot/Latin square/blocked/randomised/exhaustive & 2 \\
\hline \multirow[t]{3}{*}{ Duration of experiment } & $10-19$ years & 0 \\
\hline & $20-29$ years & 1 \\
\hline & $\geq 30$ years & 2 \\
\hline \multirow[t]{3}{*}{ Soil sampling depth } & Shallow $(<15 \mathrm{~cm})$ single or multiple sampling & 0 \\
\hline & $\begin{array}{l}\text { Plough layer }(0-25 \mathrm{~cm}) \text { single or multiple sampling, or deep }(>25 \mathrm{~cm}) \\
\text { single sampling }\end{array}$ & 1 \\
\hline & Multiple deep sampling (>25 cm) & 2 \\
\hline
\end{tabular}

data (i.e., study findings) will be described (outcome type, units, data location, measure of variability, presence of bulk density) and extracted. Meta-data will be extracted into one database describing all studies, whilst quantitative data will be extracted into separate spreadsheets for each study for transparency.

\section{Synthesis}

A narrative synthesis of the evidence base will be undertaken using tables and figures that both describe the evidence base itself and the findings of individual studies. In addition, non-linear quantitative meta-analytical modelling will be performed where possible. This modelling approach involves the estimates of intercepts and slopes for $\mathrm{C}$ decay or accumulation curves. These coefficients will then be used themselves to calculate effect sizes (raw mean difference) for each included study. Studies will be combined in meta-analyses that employ the following: i) sensitivity analyses to investigate the influence of study validity (critical appraisal) and soil depth, and ii) subgroup analyses to investigate the difference between summary effect estimates for the major intervention groups identified (amendments, crop rotation, fertiliser, and tillage). Where multiple analyses are performed using the same data set levels of significance ( $\alpha$ ) will be adjusted accordingly to avoid issues relating to multiplicity of p-values.

\section{Authors' contributions}

This review protocol is based on a draft written by NH. All authors assisted in editing and revising the draft. All authors read and approved the final manuscript.

\section{Author details}

${ }^{1}$ Mistra Council for Evidence-Based Environmental Management (EviEM), Royal Swedish Academy of Sciences, P.O. Box 50005, 10405 Stockholm,

Sweden. ${ }^{2}$ Department of Biology, Lund University, 22362 Lund, Sweden.

${ }^{3}$ Department of Land, Air and Water Resources, University of California Davis,
One Shields Avenue, Davis, CA 95616, USA. ${ }^{4}$ Department Ecology, SLU, P.O. Box 7044, 75007 Uppsala, Sweden. ${ }^{5}$ Joint Research Centre, Institute for Environment and Sustainability, Land Resource Management, European Commission, 21027 Ispra, VA, Italy. ${ }^{6}$ Department of Agroecology, Aarhus University, P.O. Box 50, 8830 Tjele, Denmark. ${ }^{7}$ Department of Statistics, Lund University, 22007 Lund, Sweden.

\section{Acknowledgements}

This protocol and the forthcoming review are financed by the Mistra Council for Evidence-Based Environmental Management (EviEM). The authors thank two anonymous reviewers whose advice improved this protocol.

\section{Competing interests}

The authors declare that they have no competing interests.

Received: 12 November 2015 Accepted: 14 January 2016

Published online: 29 January 2016

\section{References}

1. Kucharik CJ, Brye KR, Norman JM, Foley JA, Gower ST, Bundy LG. Measurements and modeling of carbon and nitrogen cycling in agroecosystems of Southern Wisconsin: potential for SOC sequestration during the next 50 years. Ecosystems. 2001:4(3):237-58.

2. Mestdagh I, Sleutel S, Lootens P, Van Cleemput O, Beheydt D, Boeckx P, et al. Soil organic carbon-stock changes in Flemish grassland soils from 1990 to 2000. J Plant Nutr Soil Sci. 2009;172(1):24.

3. Lal R, Delgado J, Groffman P, Millar N, Dell C, Rotz A. Management to mitigate and adapt to climate change. J Soil Water Conserv. 2011;66(4):276-85.

4. González-Sánchez E, Ordóñez-Fernández R, Carbonell-Bojollo R, VerozGonzález O, Gil-Ribes J. Meta-analysis on atmospheric carbon capture in Spain through the use of conservation agriculture. Soil Tillage Res. 2012;122:52-60.

5. Poeplau C, Bolinder M, Eriksson J, Lundblad M, Kätterer T. Positive trends in organic carbon storage in Swedish agricultural soils due to unexpected socio-economic drivers. Biogeosci Discuss. 2015;12(5):3991-4019.

6. Lal R, Follett R. Soils and climate change. In: Lal R, Follett F, editors. Soil carbon sequestration and the greenhouse effect. Madison, Wisconsin: SSSA Special Publication; 2009.

7. Bolinder M, Kätterer T, Andrén $\mathrm{O}$, Ericson L, Parent L-E, Kirchmann H. Long-term soil organic carbon and nitrogen dynamics in forage-based crop rotations in Northern Sweden (63-64 N). Agric Ecosyst Environ. 2010;138(3):335-42. 
8. Hati KM, Swarup A, Dwivedi A, Misra A, Bandyopadhyay K. Changes in soil physical properties and organic carbon status at the topsoil horizon of a vertisol of central India after 28 years of continuous cropping, fertilization and manuring. Agric Ecosyst Environ. 2007;119(1):127-34

9. Yang X, Li P, Zhang S, Sun B, Xinping C. Long-term-fertilization effects on soil organic carbon, physical properties, and wheat yield of a loess soil. J Plant Nutr Soil Sci. 2011;174(5):775-84.

10. European Commission. Decision No 529/2013/EU of the European Parliament and of the Council of 21 May 2013 on accounting rules on greenhouse gas emissions and removals resulting from activities relating to land use, land-use change and forestry and on information concerning actions relating to those activities 2013.

11. FAO. The 5 pillars of action Global Soil Partnership2015 [cited 2015 29th September]. Available from: http://www.fao.org/globalsoilpartnership/ the-5-pillars-of-action/en/.

12. Taghizadeh-Toosi A, Olesen JE, Kristensen K, Elsgaard L, Østergaard HS, Lægdsmand $\mathrm{M}$, et al. Changes in carbon stocks of Danish agricultural mineral soils between 1986 and 2009. Eur J Soil Sci. 2014;65(5):730-40.

13. Sanderman J, Baldock JA. Accounting for soil carbon sequestration in national inventories: a soil scientist's perspective. Environ Res Lett. 2010;5(3):034003.

14. Paul EA, Paustian $\mathrm{KH}$, Elliott $\mathrm{E}$, Cole CV. Soil organic matter in temperate agroecosystems: Iong term experiments in North America. Boca Raton: CRC Press; 1997

15. Senthilkumar S, Basso B, Kravchenko A, Robertson G. Contemporary evidence of soil carbon loss in the US corn belt. Soil Sci Soc Am J. 2009;73(6):2078-86
16. Brady MV, Hedlund K, Cong R-G, Hemerik L, Hotes S, Machado S, et al. Valuing supporting soil ecosystem services in agriculture: a Natural Capital Approach. Agron J, doi:10.2134/agronj14.0597.

17. Kottek M, Grieser J, Beck C, Rudolf B, Rubel F. World map of the Köppen-Geiger climate classification updated. Meteorol Zeitschrift. 2006:15(3):259-63.

18. Haddaway NR, Hedlund $K$, Jackson LE, Kätterer T, Lugato E, Thomsen IK, Jørgensen HB, Söderström B. What are the effects of agricultural management on soil organic carbon in boreo-temperate systems?. Environ Evid. 2015;4(1):1. doi:10.1186/s13750-015-0049-0.

19. Haddaway NR, Collins A, Coughlin D, Kirk S. The role of Google Scholar in evidence reviews and its applicability to grey literature searching. PLoS ONE. 2015;10(9):e0138237.

20. Söderström B, Hedlund K, Jackson LE, Kätterer T, Lugato E, Thomsen IK, Jørgensen HB. What are the effects of agricultural management on soil organic carbon (SOC) stocks?. Environ Evid. 2014;3:2. doi:10.1186/2047-2382-3-2.

21. Smith P. How long before a change in soil organic carbon can be detected? Glob Change Biol. 2004;10(11):1878-83.

22. VandenBygaart SJ, Angers DA. Towards accurate measurements of soil organic carbon stock change in agroecosystems. Can J Soil Sci. 2006;86:465-71

23. Cohen J. Weighted kappa: nominal scale agreement provision for scaled disagreement or partial credit. Psychol Bull. 1968;70(4):213.

\section{Submit your next manuscript to BioMed Central and we will help you at every step:}

- We accept pre-submission inquiries

- Our selector tool helps you to find the most relevant journal

- We provide round the clock customer support

- Convenient online submission

- Thorough peer review

- Inclusion in PubMed and all major indexing services

- Maximum visibility for your research

Submit your manuscript at www.biomedcentral.com/submit

() Biomed Central 